\title{
OPERAÇÃO FLIPINHA: ENCONTRO DO SONHADOR E DO CIENTISTA EM TERRA FIRME
}

\author{
OPERAÇÃO FLIPINHA: THE MEETING BETWEEN THE DREAMER \\ AND THE SCIENTIST ON FIRM GROUND
}

João Anzanello Carrascoza ${ }^{1}$

\begin{abstract}
RESUMO
A Flip - Festa Literária Internacional de Paraty é o evento de maior magnitude do campo das letras realizado no Brasil e um dos mais expressivos do mundo. Como coordenador de um Grupo de Pesquisa CNPq, que durante dois anos investigou aspectos comunicacionais e educacionais associados ao consumo desse evento literário, e na condição de convidado da "festa" em três ocasiões, o autor do presente texto se deparou com uma questão metodológica: como abordar cientificamente a Flip sem denegar a sua experiência sensória como escritor? Sua resolução, a seguir se verá, foi unir a "ciência da poesia" à "poesia da ciência" numa mescla de ensaio e diário de campo sobre a atividade mais marcante da qual participou na "festa": o encontro com crianças da Escola Municipal Domingos Gonçalves de Abreu, no Saco do Mamanguá.
\end{abstract}

Palavras-chaves: Flipinha; Comunicação; Educação Infantil.

\begin{abstract}
The Flip - Festa Literária Internacional de Paraty - is the largest literary event in Brazil and one of the most expressive in the world. As a CNPq Research Group Coordinator, which for two years investigated communication and educational aspects associated with the consumption of this literary event, and as a guest of the "party" on three occasions, the author came across a methodological question: How to approach Flip scientifically without denying his sensory experience as a writer? His decision, as we shall see below, was to unite the "science of poetry" with the "poetry of science" in a mixture of essay and field journal on the most striking activity in which he participated in the "party": the meeting with children of the Escola Municipal Domingos Gonçalves de Abreu (Saco do Mamanguá).
\end{abstract}

Keywords: Flipinha; Communication; Children's education.

\footnotetext{
1 Atualmente é docente do Programa de Pós-Graduação em Comunicação e Práticas de Consumo da Escola Superior de Propaganda e Marketing (SP). Doutor e mestre em Ciências da Comunicação pela Universidade de São Paulo. e-mail: jcarrascoza@espm.br
} 
Revista

Debates Insubmissos

\section{NO PRINCÍPIO, OS MEUS PRINCÍPIOS}

Durante os últimos dois anos, como coordenador de um Grupo de Pesquisa, vinculado ao Programa de Pós-Graduação em Comunicação, coordenei os trabalhos da pesquisa "A Festa Literária Internacional de Paraty: comunicação, consumo e contra-hegemonia", com o objetivo de investigar aspectos relacionados ao consumo material e simbólico desse evento e possíveis interfaces com os fenômenos comunicacionais, afastando, por não ser o nosso escopo, suas conexões com os estudos literários.

Propus aos membros do grupo, ante o material bruto pesquisado e toda a discussão gerada ao longo do biênio, o desafio de produzir individualmente, ou em duplas, um artigo que abordasse algum tópico de relevância envolvendo a Flip e o foco do nosso coletivo acadêmico - os imbricamentos entre a comunicação e o consumo nas artes em geral.

Cabendo-me também a escrita de um texto, vi-me, antes de iniciá-lo, diante de um "problema" como autor-pesquisador, uma vez que estive presente, na qualidade de escritor convidado, em três edições da "festa". Na primeira delas, quando do lançamento de um de meus livros de contos, participei, na tenda principal; na segunda, estive envolvido em atividades na Flipzona, programação da Flip exclusiva para o público juvenil, e na Operação Flipinha, voltada às crianças leitoras; e, por fim, na terceira, participei de uma mesa da Flip+, espaço expandido do evento principal com ênfase em temas específicos.

A singularidade das vivências que experimentei nas três oportunidades me levaram a descartar de imediato a produção de um artigo "convencional, embora fosse (e continua sendo) o meu dever (como estudioso) produzir material nesse "estilo". Então, qual tipo de "texto" elaborar, se os procedimentos metodológicos, na ciência, são determinantes? Se negam a irracionalidade e garantem a autoridade dos resultados? E se, contudo, indispensam o sensório do investigador, não obstante a ditadura da objetividade científica?

Lembrei-me de um texto de Marin (2006), embora haja consenso sobre esse seu posicionamento entre os cientistas, no qual a autora afirma: "cada problemática demanda 


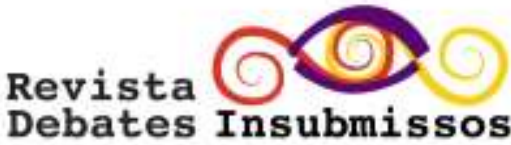

observações e caminhos diferentes de pesquisa, portanto, exige construções de procedimentos para além dos modelos pré-existentes" (MARIN, 2006, p. 66).

Lembrei-me de Marques (2019), quando afirmou em $O$ mal-estar e a anticiência, que a “ciência não é dogma, é diminuição de incerteza" (MARQUES, 2019, p.4). Lembrei-me dos riscos que eu havia corrido antes, ao publicar um artigo com "extratos líricos" e da "anomia" que seu efeito causou entre os meus pares. Impostura acadêmica? Bazófia provocativa? Desmoralização da produção publicada numa revista Qualis A2? Estudos sobre esse meu artigo, e a favor da minha "atitude", motivaram-me a não desistir de um caminho que o meu "objeto" então pedia, e renunciar à via imposta pelo padrão oficial, uma vez que não há unicamente $o$ método, mas os métodos.

Lembrei-me de antes desse antes, na época em que apresentei em congressos internacionais (IAMCR, Paris, 2008; LUSOCON, Lisboa, 2009 e ECREA, Hamburgo, 2010), e depois publiquei em livro, três artigos que, inspirados no romance ilustrado de Umberto Eco, A misteriosa chama da rainha Loana, recriavam o espaço histórico real, por meio de narrativas ficcionais, de momentos transformadores da publicidade, como 1) a emergência de seu discurso na Belle Époque francesa, 2) o aprimoramento de suas estratégias e táticas pela propaganda nazista e 3) a liquidez das ações de guerrilha publicitária com o advento da internet.

Lembrei-me de uns versos do poema $O$ artista inconfessável, de João Cabral de Melo Neto (1975): "Fazer o que seja é inútil./ Não fazer nada é inútil./ Mas entre fazer e não fazer/ mais vale o inútil do fazer" (NETO, 1975, p. 30)

Lembrei-me, por fim, das anotações que havia feito, quando da minha segunda participação na Flip, relativas especialmente a certas cenas que haviam se imantado em meus olhos na Operação Flipinha - e, então, compreendi que era um dever-devir partilhá-las, já que é próprio da ciência disseminar as evidências persuasivas de suas provas.

Assim, "pensando relacionalmente”, como propôs Bourdieu (1998) para superar a automatização do habitus científico, e com os pés fincados nos princípios que regem minha vida como pesquisador e escritor - o mundo da matéria é inseparável do mundo do sensível -, 
defini a maneira de relatar-fabular-discutir o assunto. Ou seja, o meu jeito de fazer este texto, apoiando-me em outros versos do mesmo poema de João Cabral (1975): “fazer: porque ele é mais difícil/ do que não fazer" (NETO, 1975, p.30).

\section{AINDA FAZ ESCURO: E LA NAVE VA}

Em minha última participação no evento, recebi oficialmente o convite da organização da Flip para integrar a Flipzona e a Flipinha, seis meses depois, no mês de julho, e é sobre essa, como acenei, que vou centrar o meu "relato".

$\mathrm{Na}$ sequência, recebi mensagem da escritora Anna Claudia Ramos, uma das profissionais contratadas pelo evento para produzir o material didático que seria distribuído às crianças do ensino fundamental das escolas de Paraty, no início do ano letivo, juntamente com obras dos autores convidados, com quem elas se encontrariam, futuramente, durante a realização do evento.

Na ocasião, Anna Claudia me pediu a relação de minhas obras "infantis", sem que soubéssemos qual delas seria escolhida para ser entregue às crianças - e, menos ainda, que tipo de atividade dialógica elas elaborariam sob o comando dos professores para a nossa futura interação.

Uma das críticas recorrentes nos artigos que lemos sobre a Flip nas reuniões mensais do grupo de pesquisa, e com as quais concordávamos, era o caráter "invasivo" da Flip em Paraty: na "grande tenda" se desdobrava uma programação voltada unicamente para o público externo, que para lá se deslocava, sem compromisso com o patrimônio histórico da cidade. À população local, incapaz de pagar o preço dos ingressos, nada era oferecido senão o esquecimento - a instalação de telões na rua, que reproduziam o que se passava no palco da grande tenda, embora louvável, jamais diminuiria o abismo entre os habitantes de uma das cidades mais violentas do Estado do Rio de Janeiro e os escritores convidados (brasileiros e estrangeiros) que abandonavam seus gabinetes para serem ouvidos por centenas de pessoas (vindas de todos os canto do país) num espaço confortável. Outras ressalvas: a predominância de autores publicados 


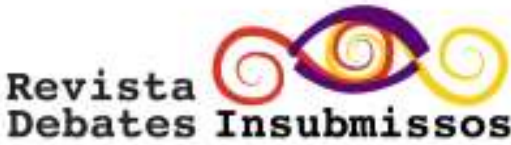

por uma única e grande editora, a cobertura "espetacular" da Rede Globo, o silêncio em relação às temáticas das minorias, o culto aos troféus do campo literário (BOURDIEU, 1996).

Por outro lado, se havia (e continua havendo) no âmbito da Flipinha, atividades para crianças levadas à cidade pelos pais "forasteiros" - a plateia principal do evento é mesmo exógena -, pude comprovar que há também um trabalho de formação de leitores junto à comunidade de Paraty, quando recebi esse material didático produzido para os alunos do ensino fundamental - e, sobretudo, quando, em julho, visitei a Escola Municipal Domingos Gonçalves de Abreu e me surpreendi com a "arte" que os estudantes haviam feito a partir de um de meus livros.

Difícil não antecipar lampejos, ou como nomeou Elena Garro (2018), “lembranças do porvir", mas, tal qual o sonhador de Fernando Pessoa (2001), que finge a dor que deveras sente - todo sonho é poesia -, vivo como escritor do ir-e-vir do passado ao presente, e desse àquele. O baralho da memória às vezes dá as cartas erradas, como se a redução da incerteza pudesse nos garantir o alcance da certeza.

Pois então: retomemos a ordem dos fatos, como se as palavras comandadas pela sintaxe não alterassem as múltiplas combinações do resultado. Estamos em Paraty, dia primeiro de julho. Amanhã visitarei a Escola Municipal Domingos Gonçalves de Abreu. Mas, diferente dos outros escritores, como Luiz Ruffato - com quem dividi horas atrás uma mesa inserida na programação da Flipzona -, que conversará com os alunos de uma escola no centro de Paraty, recebo a notícia de que a "minha" está situada fora da cidade, precisamente no Saco do Mamanguá, espécie de fiorde tropical, acessível apenas de barco. E outra informação, mais surpreendente ainda: "vamos" partir do cais - pois haveria uma comitiva me acompanhando! às cinco e meia da manhã.

Eis que estamos já nesse outro dia. Apanham-me na pousada às cinco e pouco e me conduzem até o ancoradouro. A noite avança e, em breve, vai se ajoelhar aos pés do sol, para que um novo dia reine. Observo ao longe a Igreja de Santa Rita iluminada. Em solidão, ela segue sagrada na paisagem, ao menos nessa hora, antes que o vozerio dos turistas profane (logo cedo) a sua paz. Dezenas de embarcações estão atracadas, ondulando levemente no escuro - só 


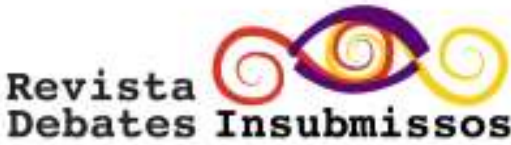

há uma escuna, no fim do cais, com as luzes acesas e umas pessoas à sua beira. Sei que é nela que vou navegar. Sinto às minhas costas a vibração que povoou a cidade até horas atrás - a festa dos boêmios, dos amantes da literatura, e, também, dos indiferentes (que aqui vieram por outros motivos).

Na janela (página branca) dessa outra janela - o programa word do Windows -, estou me vendo como um observador alheio, ou me revendo numa curva do tempo dobrável unicamente graças à evocação que a palavra, de mãos dadas com a memória (ainda que falha), nos permite. Naquela madrugada, eis que sou o sonhador. Nesse instante, o cientista. Uns versos de Nicanor Parra (2018), com a sua anti-poesia (que se alinha à anti-ode de João Cabral), lembram-me que a arte e a ciência são dois braços de um mesmo corpo:

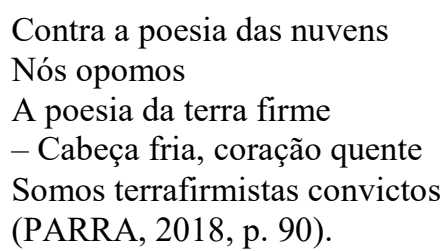

Einstein, para chegar à relatividade, andava nas nuvens ou em solo sólido? Conrad, para atingir o coração das trevas, não se valeu de uma estratégia náutica?

Fourez (1995) afirma que "observar é estruturar um modelo teórico" (FOUREZ, 1995, p. 39). Conforme avanço no cais, observo um homem em destaque entre as pessoas que me aguardam junto à escuna. Ainda que não se mova, noto que está pronto para me acolher com um abraço. Seria o comandante? De certa forma, sim, logo descobrirei. Volnei Canônica, do Instituto Cultural C\&A de Desenvolvimento Social (programa Prazer em Ler). Ele não conduzirá o barco, mas, como líder escalado para essa "operação", vai coordenador a nossa viagem. Vai me dar as boas-vindas, apresentar-me a Patricia Lacerda, que atua no mesmo instituto, explicar-me brevemente o nosso itinerário, e, quando estivermos navegando, passará a palavra a cada uma das pessoas da comitiva para que se apresentem.

Entro na escuna, cumprimento a todos que me saúdam com sorrisos: somos estranhos, eu penso. Mas daqui a pouco amanheceremos juntos. Como no poema "Morte do leiteiro" de Drummond (1977), em breve, "por entre os objetos confusos/ mal redimidos da noite", duas 


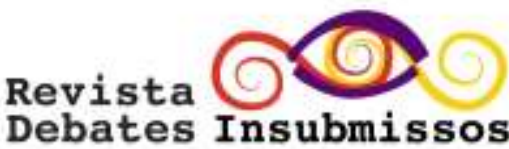

cores vão se procurar, suavemente se tocar, amorosamente se enlaçar, "formando um terceiro tom/ a que chamamos aurora" (DRUMMOND, 1977, p.127).

Penso, não naquela hora, mas nesse instante (da escrita), que estou em verdade exercendo a flânerie como método acadêmico, investigando não mais nas ruas da cidade como o flâneur clássico - Baudelaire por Benjamin (1989) -, mas flagrando nas estradas vicinais da memória signos que me guiam "livremente" pelas águas da compreensão. A descoberta se dará no durante dos fatos, a vida definida não como um ponto estelar de início, nem como o pontocruz do fim, mas como o intervalo (comprido para uns, breve para outros) entre ambos.

Penso na distância existente entre o estado de poesia vivido e a sua recordação. Anose-anos-luz. O que nos resta, para arrastar o outro a essa "mesma" experiência, senão reconstruíla pela linguagem? O vivido já foi vivido, cumpriu a sua vez, mas não está morto. O vivido volta como o santo ao altar das tentações. Âncora recolhida: a escuna, enfim, vai partindo rumo ao Mamanguá.

\section{O PRIMEIRO (E INESPERADO) ENCONTRO}

A bordo, duas dezenas de agentes de leitura de várias partes do Brasil, jornalistas, representantes de editoras, curadores de eventos literários como Tania Rösing, da Jornada Literária de Passo Fundo (lá estive em 2013, a seu convite). Com exceção dela, é meu primeiro encontro com os demais ali embarcados. E enquanto o microfone passa de mão em mão, cabendo a cada um dizer umas palavras sobre si e seu trabalho, vamos nos saciando diante da exuberante mesa de frutas, sucos, pães, salgados, doces, bebidas quentes e frias que nos prepararam de café da manhã.

Eis quem somos nessa hora (e nas outras): errantes navegantes sobre a pele da Terra. Não por acaso, os versos de Caetano Veloso (2019), sobre o nosso planeta, ecoam nos meus ouvidos: "do mar se diz terra à vista/ terra para o pé firmeza/ terra para a mão carícia" (VELOSO, 2019, online). Uma pausa se faz, não sei se de propósito: para admirarmos a cidade da qual nos distanciamos, ouvindo o motor da escuna deslizando pelo mar. Para que as vozes 


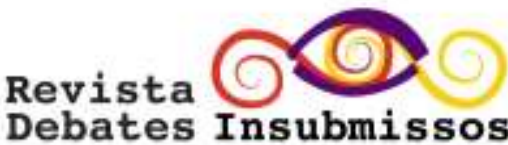

humanas se calem por um momento. A jornalista Tânia Rego então se aproxima do tombadilho onde estou e me aborda com algumas perguntas. Linda, depois, a matéria que ela fez a partir dessa "entrevista" e as imagens que captou durante a nossa "operação". Como nunca a mais a vi, por meio deste texto eu a agradeço. Ali permanecemos um tempo, distantes dos demais "passageiros, com os rostos respingados de oceano Atlântico. Todos já se apresentaram. E, como se dominado pelo vaivém das ondas, ciente de que as marés da inexistência podem me afogar a qualquer instante, salto no tempo, daquele lá para o presente aqui, e reafirmo: foi o primeiro encontro. Porque, depois, o segundo se deu entre mim e muitos dos que estavam lá, como se fosse nosso destino uma segunda vez: para nos olharmos, frente a frente, e reconhecermos aquela epifania que "então" se deu. Volnei Canônica: encontrei-o ainda no final deste mesmo ano, quando, na qualidade de diretor do Programa de Livro, Leitura, Literatura e Bibliotecas, do Ministério da Cultura, estivemos na cerimônia de entrega do prêmio Jabuti. Patricia Lacerda: três anos depois, num jantar oferecido pela Fundação Biblioteca Nacional. Bruno Sousa de Araújo e Sidinéia Chagas: dois anos e meio depois, quando estive na Biblioteca de Parelheiros, a convite de Bel Santos (outra maravilha foi conhecê-la, inesperadamente, num evento, um ano depois, na Cidade do México, e, porque, retomando Caetano Veloso (2019, online), "gente é outra alegria/ diferente das estrelas"). E a lista dos segundos encontros segue; daí que, para não perder o foco, fecho-a com um etcétera.

Pelas fotos de Tânia Rego e as faces que minha memória borra, pude (e posso) me encontrar, sobretudo, embora não fisicamente, com as crianças que, nesse diário de campo (de um dia só) a posteriori, ainda não apareceram - mas são o motivo de minha escrita. Leitoras das árvores do Mamanguá, de seu nascer do sol, de seus silêncios verdes. Elas quem, no fundo, me trouxeram para essas linhas feitas de tempo e palavras provisórias.

Pergunto-me se estou sendo fiel ao "meu" método e à ciência. Recordo-me da expressão “idiotas da objetividade”, concebida por Nelson Rodrigues (2018). Recorro novamente a Marin (2006), ao dizer que o diário de campo "é um recurso importante para registrar formas de comunicação que instrumentos tecnológicos nem sempre captam: as emoções, as sensações, os 
comportamentos kinésicos, e traz para a pesquisa dimensões vitais e, muitas vezes, negadas pelo saber científico".

Continuamos a nossa jornada. Conversas se entrecruzam à medida que a escuna avança, sem os lendários argonautas. Somos somente nós, amantes da leitura, do livro, do prazer de ler. Observo-os com a distância de quem conhece os desdobramentos do enredo que vivemos juntos e está contaminado pela gratidão. Ocorre-me uma consideração de Duarte (2016): "nunca pensamos sozinhos, todo grande insight se deve ao alicerce de conhecimento que nos formou e não há copo de cristal com uso que não traga marcas de nossas digitais" (DUARTE, 2016, p. $35)$.

Uma ave marinha atravessa o céu, grasnando. Penso no sonhador e no cientista que convivem em mim. Lembro-me do poema de Baudelaire (2012) sobre a semelhança do poeta com o albatroz: "Exilado no chão, em meio à turba obscura, / As asas gigantes impedem-no de andar" (BAUDELAIRE, 2012, p. 13).

Por acaso, e como o acaso é uma variável do processo criativo, tão bem explicado por Salles (1998), estou lendo poemas de Yehuda Amichai (2018) e os transporto uns versos seus para cá. Eu, a escuna que lhes tira do ontem fixo e os conduz ao eterno presente (da leitura): "Vê, tivemos mais do que vida,/ agora precisamos avaliar tudo/ nos sonhos pesados e atiçar/ memórias rapinantes no agora" (AMICHAI, 2018, p. 153).

Terra à vista, o fiorde é nosso. Já vejo o Saco do Mamanguá no horizonte da escrita. Espaço aéreo para liberar outras memórias rapinantes.

\section{VENHAM A NÓS AS CRIANÇAS!}

Vamos nos aproximando do pequeno atracadouro. O céu clareou, o dia recém-nascido se abre sem pressa, no ar o denso aroma da maresia. À nossa frente, um bloco de verde vivo, a mata com suas dobraduras arbóreas. Mas onde a escola? A escola ainda irrevelada, daqui a pouco será descoberta, quando subirmos, em fila, por uma vereda ladeada de pedras e arbustos. 


\section{Revista \\ Debates Insubmissos}

Desembarcamos sem pressa (Fig. 1). Alguém diz que chegamos antes das crianças.

Figura 1: Desembarque da comitiva da "Operação Flipinha" em Mamanguá.

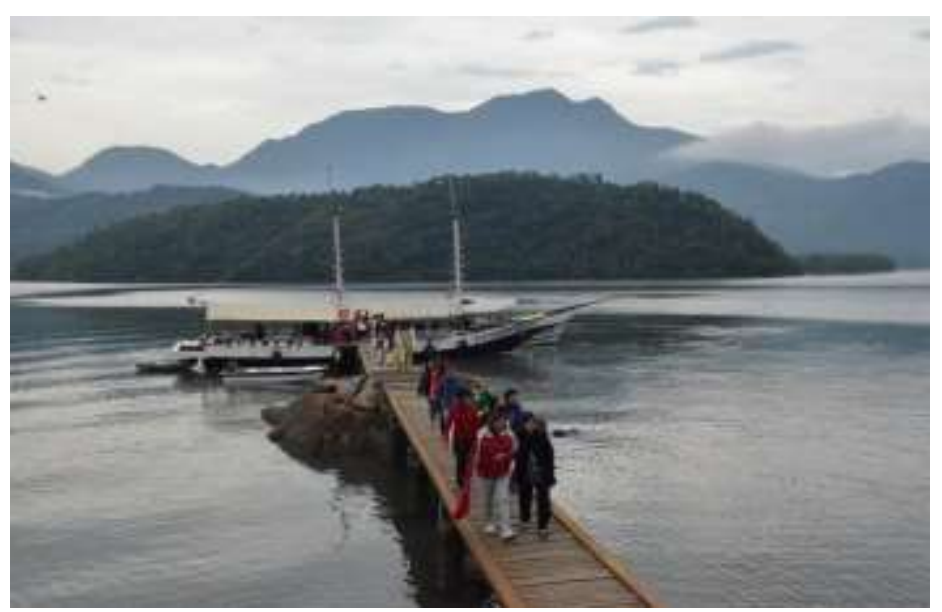

Fonte: Arquivo do autor.

Uma "sorte", já que do cais podemos observar os pequenos barcos que se acercam, trazendo-as para nós. Ficamos ali, assistindo à sua aproximação para lhes dar as boas-vindas, nós - que adentramos ao seu santuário sem pedir permissão.

Assim, poderemos vê-las também em terra, desembarcando e correndo, ansiosas, por aquele seu trecho de mundo, em nossa direção (Fig. 2). Descontraídas umas, intimidadas outras. Estudando-nos face a face, ou à distância. Um inesperado pré-teste, interação informal e sincera, descumprindo (para a nossa surpresa e alegria) o protocolo.

Figura 2: Chegada dos alunos da Escola Municipal Domingos Gonçalves de Abreu.

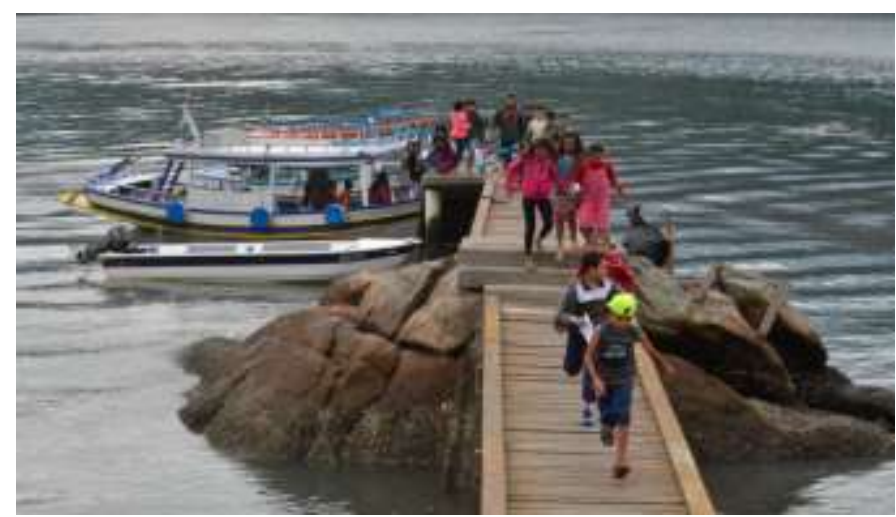

Fonte: Arquivo do autor 
Caminhamos juntos, a comitiva da Operação Flipinha e as crianças, e, pela vereda, alcançamos a escola, oculta na mata, finalmente desenglobada para os nossos olhos. Pequenos cartazes sobre o meu Livro X pendem em uma de suas paredes, junto a uma faixa da prefeitura de Paraty. Lá dentro, os professores nos esperam. Aqui fora, os alunos se acomodam no chão, dispersam-se, donos de seus movimentos, como se não fosse (ao menos para mim) um dia raro, flor nascida da planta espinhosa da rotina (Fig. 3).

Figura 3: Escola Municipal Domingos Gonçalves de Abreu, Saco do Mamanguá.

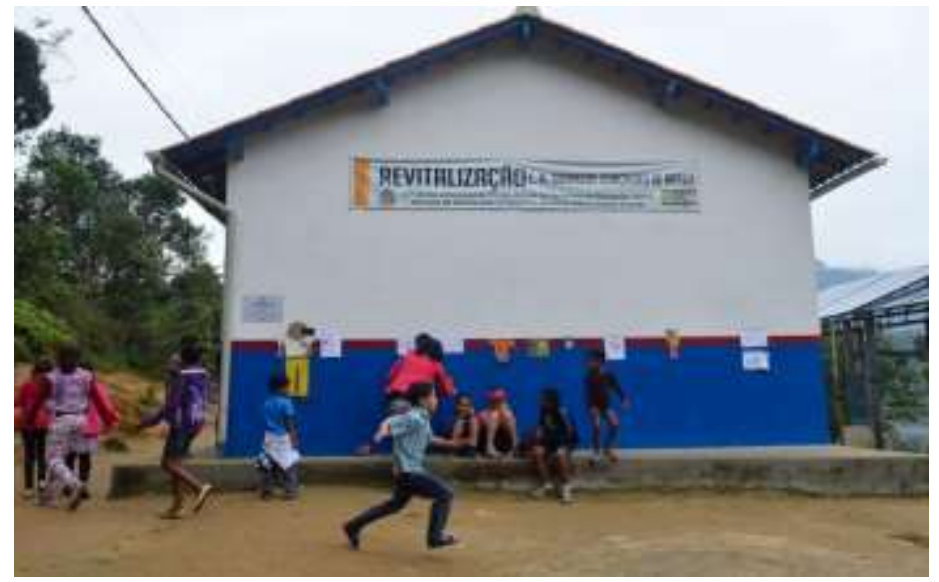

Penso na "técnica" de observação participativa. Não a empreguei à época. Não imaginava que viveria esse acontecimento. Então penso agora: o que faço não é senão uma “evocação" participativa! De novo, a minha lente de pesquisador focaliza o sonhador que eu era naquele momento.

Entramos na escola. Uma professora nos informa que, como um dia letivo normal, os alunos tomam o café da manhã antes da aula - aliás, já fazem fila diante da cozinha (Fig. 4). 
Figura 4: Crianças à espera do café-da-manhã.

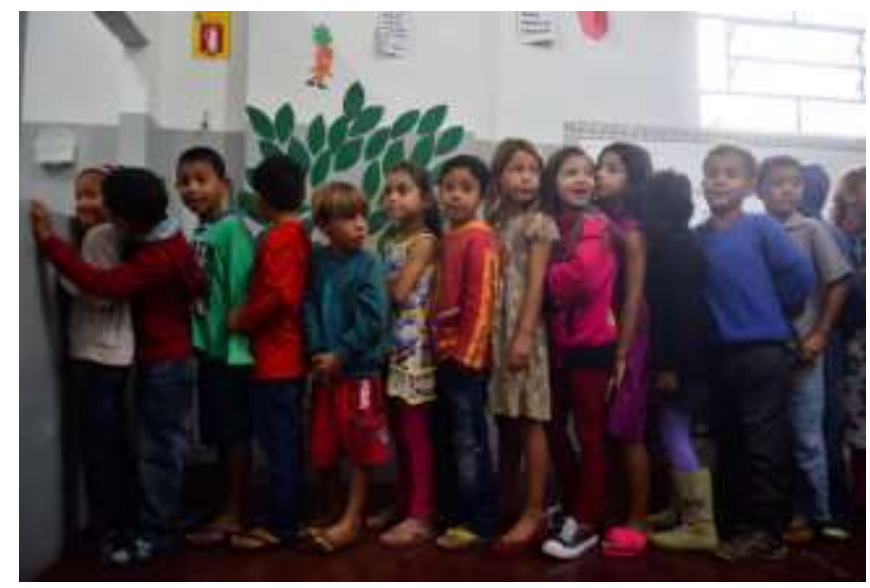

Fonte: Arquivo do autor.

Enquanto acalmam a fome, ela nos convida a conhecer a escola: ou, na verdade, a "única" sala de aula, cujas cadeiras foram afastadas para os cantos, deixando a área central livre para a nossa conversa.

Os agentes de leitura da comitiva, acostumados a atuar em condições idênticas, nada dizem, apenas miram-remiram. Mas eu sei o que sentem, sei que estão ali porque sonham com um país leitor, com a utópica justiça social, com um mundo menos desigual.

A professora nos mostra, num canto da sala, a pequena prateleira com livros - a "biblioteca" da escola. Folheio essas poucas obras, devolvo-as. Dali mesmo, vejo pela janela umas crianças brincando lá fora, retardatárias, interessadas em saciar outra fome (Fig. 5). 


\section{Debates Insubmissos}

Revista

Figura 5: Vista de uma janela da Escola Municipal Domingos Gonçalves de Abreu.

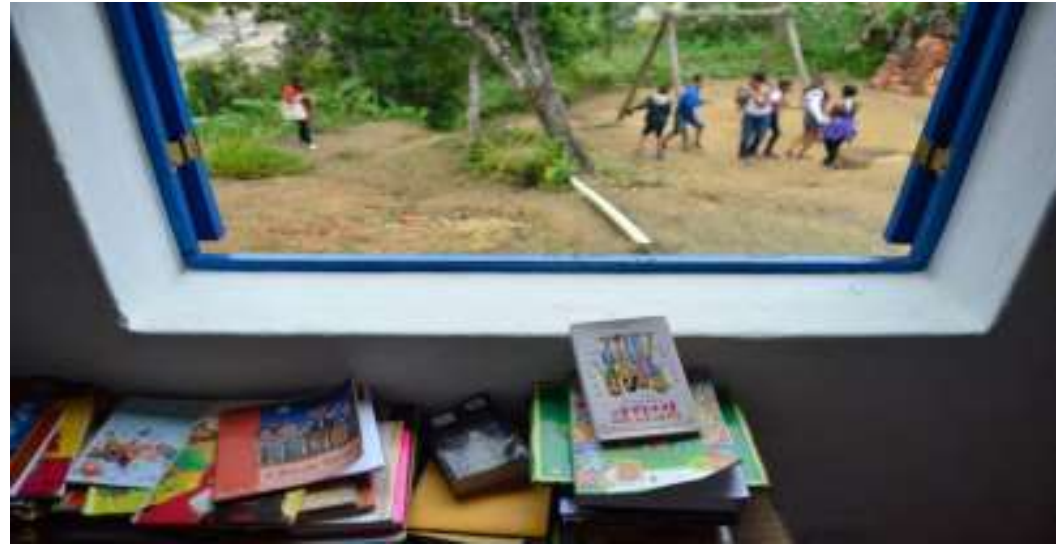

Fonte: Arquivo do autor.

Em seguida, conhecemos as "demais" áreas da escola. Estamos isolados naquele bolsão de natureza. Distantes das ruas do centro histórico de Paraty enformigadas de gente, da horda de visitantes, dos escritores estrangeiros (como Beatriz Sarlo, Leonardo Padura, Ngũgĩ wa Thiong'o) que vão se apresentar na Flip e ainda devem estar dormindo. Estranhamente, recordome daquela vez em que estive na tenda principal da festa, no palco diante de mais de duas mil pessoas. Distintas formas de solidão em meio às pessoas.

Os alunos se sentam, comandados pela própria intuição. Os adultos vão se posicionando ao seu redor como plateia, a maior parte em pé, formando involuntariamente um cinturão de proteção (como se para garantir o nosso encontro). A "cerimônia", enfim, vai começar.

Volnei Canônica toma a palavra, explica os motivos do encontro, apresenta coletivamente os agentes de leitura que vieram de várias regiões do Brasil, busca com sensibilidade retirar do momento o seu peso de ação oficial da Flipinha. Ação, contudo, que está no seu durante, pois começou em janeiro daquele ano. Por último, aponta para mim, o autor das obras que elas, as crianças, leram, e por meio do qual fizeram uma intervenção - ali viemos para vê-la.

Os alunos me olham e sorriem, alguns já me conhecem pela foto dos livros. Mesmo assim, parece que sou uma imagem virgem, não param de buscar em mim algum mistério. 
Tenho certeza que um e outro, mais afoito, gostaria de me tocar, pois, é inegável, não acreditam que eu seja eu mesmo. Mal sabem que experimento igual sensação: será que, passeando o olhar pelo rosto deles, estou na esfera do sonho ou da vigília?

Volnei entrega a palavra a uma das professoras. Vamos conhecer o outro lado da nossa história. Ela, então, explica em detalhes que, embora tenham lido obras minhas, concentraramse no Livro X. Talvez porque nele há um inventor, o Zé Traquitana, que resolve os problemas das pessoas com as suas criações, como o localizador de guarda-chuvas, o decifrador de pum, a máquina de fazer lição de casa.

A professora lê algumas poesias feitas pelos alunos a partir da história. Mostra-nos os seus respectivos desenhos e os faz correr de mão em mão. Como são duas ou três dezenas de "artes", saboreamos devagar, cruzando olhares, sorrisos, comentários cúmplices em voz baixa. A vida é mesmo aos poucos. Num único gole se perde as nuanças da alegria. E também os da dor.

\section{SOLTANDO OS SONHOS}

Depois de uma hora ali, apreciando aqueles textos e desenhos, sobrevêm o momento mágico: a professora sinaliza e dois alunos retiram de um esconderijo a "máquina de fazer sonhos", tal qual na minha história. Avisa-nos que, semanas atrás, o sonho de cada criança foi depositado na máquina - e agora serão desvelados (Fig. 6).

Figura 6: A "máquina de sonhos" inventada pelos alunos.

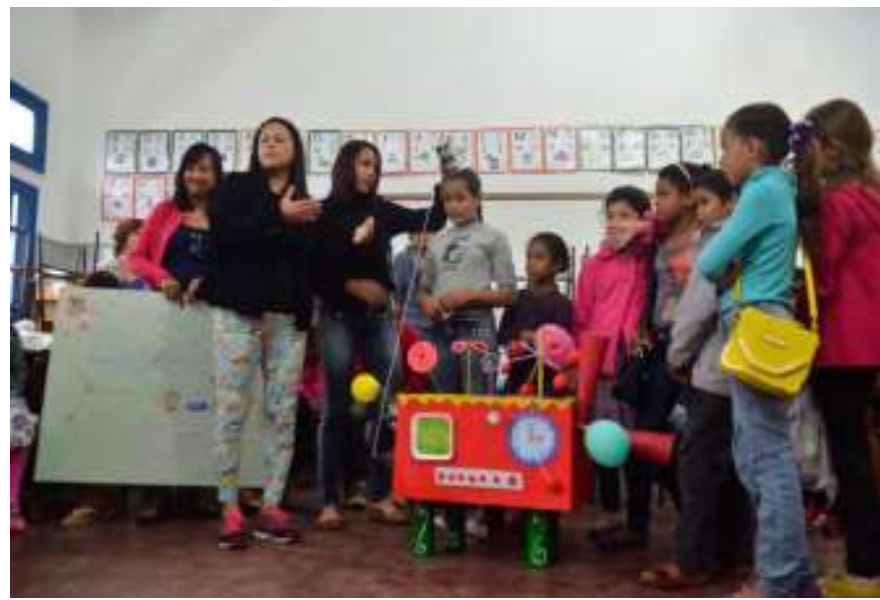

Fonte: Arquivo do autor. 


\section{Debates Insubmissos}

Revista

Duas estudantes, as mais "velhas, vão se revezando na prerrogativa de tirar os "sonhos" de dentro da máquina e anunciar o seu conteúdo, bem como quem é o seu sonhador. O primeiro sonho revelado, de um menino, é ser pescador. Na certa, como o próprio pai, o avô, a população autóctone. Penso, enquanto rememoro essa cena, em Lévi-Strauss (2005) e sua definição de bricolagem - o homem se valendo dos elementos de sua terra, do que tem à mão, para inventar artefatos distintos de outras culturas. Naquele momento, contudo, eu só ouvia, atento, a voz das meninas divulgando, um a um, os sonhos dos alunos daquela escola, do Saco do Mamanguá.

Outro menino sonha em caçar um tigre. A professora comenta que ainda existem tigres na mata das redondezas. Mogli e Shere Kahn. Pi Patel e Richard Parker. Uma menina sonha em ser top model. Kellner e a cultura da mídia me vêm à mente. Canclini (1995) também, pois consumindo (imagens, discursos, narrativas), vamos nos tornando cidadãos. E todo um corolário de prós e contras que discutimos, durante os dois anos em que estudamos a Flip. $\mathrm{O}$ objeto de pesquisa (teórico e empírico) não nos abandona (como a infância que tivemos).

A cada anúncio, palmas para o sonhador, que, entre constrangido e feliz, identificavase para os demais. Todos escondidos no sorriso de seus lábios e na simplicidade de suas roupas. Observo essas crianças: bonito vê-las confirmando silenciosamente os seus sonhos. Bonito porque eu sentia a beleza de quem observava com paixão. Porque era a vida que, pelos meus sentidos, apontava a beleza delas para mim. Por que a vida usava os meus olhos para ver beleza naquelas crianças. No silêncio daquela mata, vi a fome de ser criança e crescer - mesmo pressentindo que crescer é justamente deixar de ser, criança.

Por fim, chegou a vez de me manifestar. Na verdade, só me ocorreu agradecer. Agradecer e segredar também qual o meu sonho: poder sentir (sempre!) o que eu sentira ali. Por eles. Pelo nosso encontro.

O que importa, depois: que conversamos sobre livros, histórias, alegrias advindas das palavras. Respondi perguntas. Patricia Lacerda contou experiências comoventes que viveu com crianças de comunidades cariocas. Deixamos que a dispersão se desse com naturalidade, um encontro sem ponto final burocrático. Inacabado como toda pesquisa, como pontua Marin em relação à ciência (2006) e Salles (1998) a respeito das artes. Crianças se espalhando lá fora, 
pequenos grupos da comitiva trocando vivências, cada um de nós no domínio de sua miúda existência. Mas, antes, uma foto de todos os presentes: uma lembrança para o álbum das ausências.

Ausências que, no entanto, se esfumam nos contornos imprecisos, mas possíveis da escrita, ainda que lavada pela ideologia de quem a produz. Ocorre-me a posição de Orlandi (2005): somos discursos, atravessados por outros discursos. E, talvez, seja esse o nosso único poder, a motivação pela qual escrevemos, como tão bem disse Magris (2015): "para lutar contra o esquecimento, no desejo - talvez patético mais apaixonado - de parar, para salvar as coisas e, acima de tudo, salvar os rostos que amamos da erosão do tempo, da morte" (MAGRIS, 2015, s/p.).

\section{PALAVRAS FINAIS: O SILÊNCIO DA VOLTA}

Não há conclusão. Nem daquela-essa viagem, já que a ela retornamos, como o albatroz à terra, com o presente "relato". Nem o próprio se fecha a um concluir. Vinci (2018, p.270) nos diz que pesquisar também é fabular. Uma fábula nunca termina, nem cessa a sua capacidade de contaminar. João Cabral (1975) confirma com um poema sobre a arte da pintura:

Quadro nenhum está acabado,
disse certo pintor;
se pode sem fim continuá-lo,
primeiro, ao além de outro quadro
que, feito a partir de tal forma,
tem na tela, oculta, uma porta
quer dá a um corredor
que leva a outra e a muitas outras
(NETO, 1975, p.68)

Retomo a consideração de Marques (2019, p.4), de que a ciência "é diminuição de incerteza" (MARQUES, 2019, p.4). Não sei se reduzi algum milímetro da minha dúvida. Mas sigo acreditando no "inútil do fazer". Por acaso (acaso?), li outros poemas de Amichai (2018) e dei com uns versos, que caem bem aqui, cumprindo a ideia de que o pesquisador é um artesão e vai tramando com os fios de conhecimento a sua obra: "Do lugar onde sempre estamos certos/ nunca brotarão/ flores na primavera" (AMICHAI, 2018, P.147). A poesia é ampliação (mesmo se mínima) da esperança. Universo do sensível onde o sonho sobrevive. 
Faz-se a hora da despedida. Abraços, beijos, a alta voltagem dos sentidos. Os alunos saem às corridas para pegar o barco e voltar à casa (Fig. 7). Adeus, adeus, dizem seus passos silenciosos para nós, que vamos partir do Saco de Mamanguá depois deles. Ainda nos restou tempo para mirá-los indo embora. Nossa escuna nos aguarda ao sol das onze da manhã.

Figura 7: Crianças da “Operação Flipinha” deixando o Saco do Mamanguá.

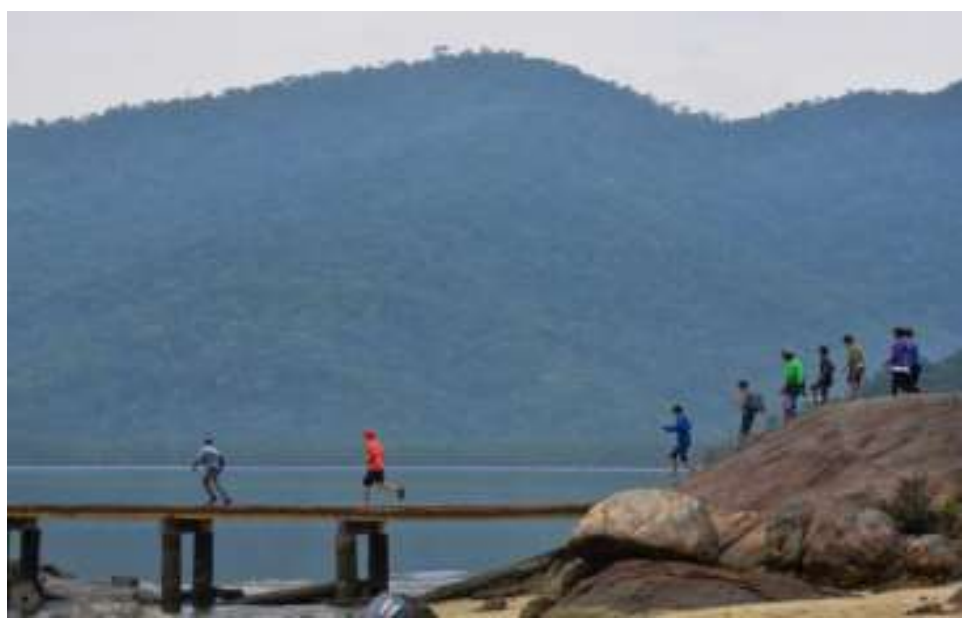

Fonte: Arquivo do autor.

Nosso retorno é singrado pelo silêncio. Vamos quietos, e, quando um e outro pescam palavras, essas são macias, sem anzóis. Nesse momento, observando os agentes de leitura que estiveram comigo, encontro a definição de literatura - que vou repetir pelos anos seguintes: rede de afetos.

O microfone, aberto ao uso, seguirá mudo. Volnei Canônica só o tomará quando estivermos chegando a Paraty, o casario da cidade imóvel em sua rígida realidade, e trêmulo nas águas da baía. Estamos todos (é um sentimento meu, talvez não do mundo) atentos às batidas do coração da experiência que vivenciamos há pouco, como quem encosta uma concha marinha no ouvido e se deleita com os seus ecos.

Penso na Flip como um polissistema. Procuro um trecho dos muitos textos que lemos de Even-Zohar (2013), para abordar nosso objeto de pesquisa. Encontro-o e o insiro, a seguir: as crises e catástrofes "de um polissistema (isto é, fatos que precisam uma mudança radical 
sejam por transferência interna ou externa), se o sistema as controla, são indícios de vitalidade mais que de degeneração" (EVEN-ZOHAR, 2013, p.19).

Vou à popa da escuna, miro pela última vez o Saco do Mamanguá e vejo os sulcos que a escuna vai deixando no mar lá atrás. Penso nas críticas que a Flip angariou desde o seu advento. E penso, igualmente, como condiz ao cientista, na força oposta, rica e produtiva, que ela gerou: o Circuito Off Flip (com seu prêmio literário e seu selo editorial), a Flipei (Festa Literária Pirata das Editoras Independentes (e seu Barco Pirata), as casas parceiras (Casa Folha, Casa do Desejo, Casa Paratodxs, Casa Sesi etc.), a Paraty Real e outras iniciativas vivas e vicejantes graças unicamente ao "inútil" do seu fazer.

Recolho minhas asas de albatroz. A ciência não prescinde da sensibilidade, nem a poesia da razão. A máquina de fabricar sonhos do Zé Traquitana continua ligada. Atracamos no cais (e no porto inseguro desse texto) ao meio-dia. Minha mente flutua, enquanto desembarco. Terrafirmista.

\section{REFERÊNCIAS}

AMICHAI, Yehuda. Terra e paz. Antologia poética. Rio de Janeiro: Bazar do Tempo, 2018. ANDRADE, Carlos Drummond de. Antologia poética. 10a ed. Rio de Janeiro: José Olympio, 1977.

BAUDELAIRE, Charles. As flores do mal. Rio de Janeiro: Nova Fronteira, 2012.

BENJAMIN, Walter. Charles Baudelaire: um lírico no auge do capitalismo. São Paulo: Editora Brasiliense, 1989.

BOURDIEU, Pierre. As regras da arte - Gênese e estrutura do campo literário. São Paulo: Companhia das Letras, 1996.

BOURDIEU, Pierre. O poder simbólico. Rio de Janeiro: Bertrand do Brasil, 1998.

CANCLINI, N. G. Consumidores e cidadãos: conflitos multiculturais da globalização. Rio de Janeiro: Editora UFRJ, 1995. 
DUARTE, Eduardo. A experiência estética e as condições para um método. In: MENDONÇA, Carlos Magno Camargos; DUARTE, Eduardo; FILHO, Jorge Cardoso (orgs). Comunicação e sensibilidade. Pistas metodológicas. Belo Horizonte: PPGCOM UFMG, 2016.

EVEN-ZOHAR, Itamar. Teoria dos polissistemas. Revista Translatio 4, 2013, p.1-21.

FOUREZ, Gérard. A construção das ciências: introdução à filosofia e à ética das ciências. São Paulo: UNESP, 1995.

GARRO, Elena. As lembranças do porvir. Curitiba: Arte e Letra, 2018.

LÉVI-STRAUSS, Claude. O pensamento selvagem. São Paulo: Papirus, 2005.

MAGRIS, Claudio. Conferência ministrada na UCLA (University of California, Los Angeles) em 18/05/2015.

MARIN, Elizara Carolina. O ofício da pesquisa: processos do fazer. In: MALDONADO et al (Orgs.). Metodologias de Pesquisa em Comunicação: olhares, trilhas e processos. Porto Alegre: Sulina, 2006.

MARQUES, Luiz. O mal-estar e a anticiência. Ilustríssima, Folha de S. Paulo, 6 de janeiro de 2019, p.4-5.

MELO NETO, João Cabral de. Museu de tudo. Rio de Janeiro: José Olympio Editora, 1975.

ORLANDI, E. P. Análise de discurso. Princípios \& procedimentos. $6^{\mathrm{a} e d ., ~ C a m p i n a s: ~ P o n t e s, ~}$ 2005 .

PARRA, Nicanor. Só para maiores de cem anos. Antologia (anti)poética. São Paulo: Editora 34, 2018.

PESSOA, Fernando. Obra poética. Rio de janeiro: Nova Aguilar, 2001.

RODRIGUES, Nelson. O melhor de Nelson Rodrigues: teatro, contos e crônicas. Rio de Janeiro: Nova Fronteira, 2018.

SALLES, Cecilia Almeida. O gesto inacabado. Processo de criação artística. São Paulo: Annablume, 1998.

VELOSO, Caetano. Terra. Disponível em: https://www.letras.com.br/caetano-veloso/terra. Acesso em: 21 de janeiro de 2020.

Submetido: 06/05/2021

Aprovado: 19/07/2021

REVISTA DEBATES INSUBMISSOS, Caruaru, PE. Brasil, Ano 4, v.4, no 13, mai./ago. 2021. ISSN: 2595-2803

Endereço: https://periodicos.ufpe.br/revistas/debatesinsubmissos/ 